\title{
Proliferative activity in human glioblastomas: evaluation of different Ki67 equivalent antibodies
}

\author{
Sverre H Torp
}

\begin{abstract}
Aims-Determination of proliferative activity in human gliomas may be of clinical importance. Immunohistochemical estimation of the proliferative index with the prototypic monoclonal antibody $\mathrm{Ki} 67$ is often used but has the disadvantage that it must be carried out on frozen material. However, novel Ki67 equivalent antibodies have been developed for use on formalin fixed and paraffin wax embedded tissue. In this study, the prototypic Ki67 antibody and several new Ki67 equivalent antibodies were tested on human glioblastoma tissue.

Methods-Eleven glioblastomas were included in the study. The antibodies used were the prototypic monoclonal Ki67 and the novel Ki67 equivalent antibodies MIB1 (monoclonal), NC-MM1(monoclonal), NC-Ki67p (polyclonal), and rabbit antihuman Ki67 antigen (polyclonal). The prototypic Ki67 was used on frozen sections and the other Ki67 antibodies on microwave oven heated, formalin fixed and paraffin wax embedded sections.

Results-All antibodies exhibited specific granular nuclear staining of weak to strong intensity. In some tumours the labelling indices were within the same range, whereas in others the antibodies elicited divergent values.

Conclusions-All the novel Ki67 equivalent antibodies provided satisfactory staining on paraffin sections. However, a significant spread of labelling indices was recorded in some cases. Therefore, Ki67 immunostaining is encumbered with some degree of uncertainty and requires further optimisation before it can be regarded as a reliable prognostic marker. (F Clin Pathol: Mol Pathol 1997;50:198-200)
\end{abstract}

\section{Institute of}

Morphology and

Department of

Pathology, Norwegian

University of Science

and Technology,

Faculty of Medicine,

Trondheim University

Hospital, Trondheim,

Norway

Correspondence to

S H Torp, Department of

Pathology, Trondheim

University Hospital, N-7006

Trondheim, Norway.

Accepted for publication 6 March 1997 antibody $\mathrm{Ki67}$, which is reactive against nuclear antigen expressed in proliferating cells. ${ }^{12}$ Its clinical use has been demonstrated in several reports. ${ }^{3}$ In human astrocytomas, the Ki67 labelling index correlates well with other proliferation markers, with histological grade,

Current opinion is that the faster a tumo mation more malignant it is, and therefore, be of diagnostic and prognostic and with prognosis. ${ }^{4-11}$ The major drawback of the original Ki67 antibody is the requirement for frozen tissue. However, a new generation of Ki67 equivalent antibodies for use on formalin fixed and paraffin wax embedded sections has been developed. ${ }^{12-14}$ So far, few comparative immunohistochemical studies of the Ki67 equivalent antibodies have been published. ${ }^{15-18}$

The aim of this prospective methodological study was to compare various $\mathrm{Ki} 67$ equivalent antibodies on human glioblastoma tissues. Here, we expand our earlier immunohistochemical study ${ }^{18}$ and include additional commercially available Ki67 equivalent antibodies.

\section{Methods}

Eleven glioblastoma patients were operated on at the department of neurosurgery, Trondheim University Hospital, Norway and tumour samples were submitted to the department of pathology for frozen section analyses. The glioblastomas were graded according to WHO criteria. $^{19}$

Frozen sections were cut and stored at $-50^{\circ} \mathrm{C}$ until analysis. They were then air dried, fixed in acetone, air dried again, and incubated with the prototypic Ki67 for one hour at room temperature. The remaining tumour samples were thawed, fixed in buffered $4 \%$ formalin (for not longer than six hours), and embedded in paraffin wax for light microscopy. After microwave oven heating (for two times five minutes at $600 \mathrm{~W}$ in $10 \mathrm{mM}$ sodium citrate buffer, $\mathrm{pH}$ 6.0), these paraffin sections were incubated with the novel Ki67 antibodies. Details of the antibodies are shown in table 1. Formalin fixed and paraffin embedded tumour samples sent for frozen section analysis were used in the immunohistochemical analyses with the Ki67 equivalent antibodies to reduce the effect of tumour heterogeneity. There is a possibility that the membrane may rupture during the freezing process, with subsequent leakage of antigen on thawing; therefore, all the tumour samples were handled in the same way. In general, however, immunohistochemical analyses should be performed on unfrozen, formalin fixed, and paraffin embedded sections.

A standard avidin-biotin peroxidase technique was used (Vectastain ABC kit; Burlingame, California, USA) with diaminobenzidine as chromogen, and the sections were counterstained with haematoxylin. Duplicate staining on the same tumour tissues was performed with two of the antibodies (MIB1 and rabbit antihuman Ki67 antigen) using an immunohistostainer (Dako TechMate 500; Glostrup, Denmark), and the staining procedure was

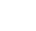

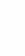

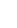
(1) (n) (1) 
Table 1 Antibodies used in the study

\begin{tabular}{|c|c|c|c|c|c|c|c|}
\hline Antibody (reference) & Immunogen & Clone & Type & Source & Used on & Methods & Dilution \\
\hline $\mathrm{Ki} 67^{12}$ & Ki67 antigen & Ki67 & MoAb & Dako & FS & $\mathrm{ABC}$ & $1: 25$ \\
\hline $\mathrm{MIB}^{1213}$ & RcKi67p & MIB1 & $\mathrm{MoAb}$ & Immunotech & PS & $\mathrm{MW}, \mathrm{ABC}$ & $1: 100$ \\
\hline NC-MM1 $1^{12} 13$ & RcKi67p & MM1 & MoAb & Novocastra & PS & $\mathrm{MW}, \mathrm{ABC}$ & $1: 100$ \\
\hline NC-Ki67p $p^{1213}$ & RcKi67p & & PolyAb & Novocastra & PS & $\mathrm{MW}, \mathrm{ABC}$ & $1: 100$ \\
\hline $\begin{array}{l}\text { Rabbit antihuman Ki67 } \\
\text { antigen }^{14}\end{array}$ & RcKi67p & & PolyAb & Dako & PS & MW, ABC & $1: 150$ \\
\hline
\end{tabular}

RcKi67p, recombinant Ki67 peptide; MoAb, monoclonal antibody; PolyAb, polyclonal antibody; FS, frozen section; PS, paraffin wax embedded section; $A B C$, immunohistochemistry using avidin-biotin-peroxidase technique; MW, pretreatment in microwave oven.

performed according to the purveyor. In each staining run, human tonsils served as positive controls, and in the negative controls the primary antibody was omitted.

The Ki67 labelling index was defined as the percentage of positively stained tumour cell nuclei regardless of staining intensity. Five random representative areas were evaluated at a magnification of $\times 400$ using an eyepiece grid and a total of $1000-4000$ cells were counted in each case. In addition, the heterogeneity of the immunostaining and the degree of background staining were evaluated. Areas with necrosis and vascular proliferation were excluded.

\section{Results}

A summary of the labelling indices obtained for each tumour with each of the antibodies is shown in table 2. The original Ki67 worked well on cryosections, whereas on microwaved paraffin wax sections the immunostaining was highly variable, often with disturbing background and cytoplasmic staining. In contrast, all the novel Ki67 equivalent antibodies demonstrated positive immunostaining in microwaved paraffin wax sections. The monoclonal Ki67 equivalent antibodies gave distinct granular nuclear staining with no non-specific diffuse or cytoplasmic staining. In general, the smaller tumour cells were immunolabelled. The staining intensity varied from weak to strong and the positive tumour cells were distributed at random in the tumour; sometimes groups of positive cells were located in the vicinity of vessels. The polyclonal Ki67 equivalent antibodies revealed weak background staining in a few cases, either diffuse and/or weak cytoplasmic, sometimes in gemistocytic astrocytes.
In the duplicate immunostainings no differences were observed with regard to staining quality. However, differences in labelling indices were recorded; both between the two staining experiments and between the two antibodies in the second staining run. In some tumours the labelling indices obtained with the different antibodies were within the same range (tumours $1,2,7$, and 10), in other tumours a relatively small spread of values was observed (tumours 6 and 8), whereas in the remaining tumours a marked spread of values was recorded.

\section{Discussion}

This study expanded our earlier investigation of Ki67 immunostaining on paraffin wax sections of human glioblastomas ${ }^{18}$ by using several novel Ki67 equivalent antibodies. The antibodies elicited matching labelling indices in some tumours although divergent values were recorded in several cases.

To our knowledge this is the first study in which a panel of $\mathrm{Ki} 67$ equivalent antibodies has been tested on paraffin wax sections of human glioblastomas. The staining correlated with that of the prototypic Ki67 on frozen sections. The prototypic Ki67 provided satisfactory staining on such tissue and the labelling indices recorded were in agreement with others. ${ }^{4-11}$ Recently, we have experienced highly variable immunostaining with this antibody when using paraffin sections that have been microwave oven heated. ${ }^{18}$ Similar observations have been made by others, ${ }^{13} 182021$ confirming the main practical disadvantage of this antibody, the lability of its epitope, limiting its use to frozen sections.

Table 2 Results of Ki67 labelling indices in human glioblastomas

\begin{tabular}{|c|c|c|c|c|c|c|c|c|c|c|}
\hline \multirow[b]{2}{*}{ Case } & \multirow[b]{2}{*}{ Sex/age } & \multirow{2}{*}{$\begin{array}{l}\text { Preop } \\
\text { therapy }\end{array}$} & \multirow[b]{2}{*}{ Site } & \multirow{2}{*}{$\begin{array}{l}\text { Ki67 } \\
(F S)\end{array}$} & \multicolumn{2}{|c|}{$M I B 1(P S)^{\star}$} & \multirow{2}{*}{$\begin{array}{l}N C-M M 1 \\
(P S)\end{array}$} & \multirow{2}{*}{$\begin{array}{l}N C-K i 67 p \\
(P S)\end{array}$} & \multicolumn{2}{|c|}{$\begin{array}{l}\text { Rabbit-antihuman Ki67 } \\
\text { antigen }(P S)^{\star}\end{array}$} \\
\hline & & & & & $1 s t$ & $2 n d$ & & & $1 s t$ & $2 n d$ \\
\hline 1 & $M / 66$ & $S$ & $\mathrm{O}$ & 11.1 & 12.5 & 18.0 & 15.6 & 15.2 & 19.8 & 13.3 \\
\hline 2 & $\mathrm{M} / 70$ & $S$ & $\mathrm{~T}$ & 2.6 & 4.3 & 3.9 & 2.1 & 3.1 & 1.9 & 4.8 \\
\hline 3 & $F / 56$ & $S$ & $\mathbf{F}$ & 2.6 & 3.1 & 15.3 & 6.7 & 9.7 & 22.7 & No material left \\
\hline 4 & $\mathbf{M} / 83$ & $\mathrm{~S}$ & $\mathbf{F}$ & 2.9 & 3.3 & 3.2 & 6.9 & 4.1 & 10.7 & 5.8 \\
\hline 5 & $\mathrm{M} / 56$ & $S$ & $T$ & 3.7 & 1.4 & 0.1 & 4.5 & 3.1 & 11.5 & 3.7 \\
\hline 6 & $\mathrm{~F} / 81$ & $S$ & $\mathbf{F}$ & 5.1 & 2.9 & 6.1 & 3.7 & 1.9 & 3.8 & 1.7 \\
\hline 7 & $\mathrm{~F} / 30$ & RC & $\mathrm{T}$ & 6.6 & 7.2 & 7.0 & 8.6 & 7.1 & 8.1 & 7.0 \\
\hline 8 & $\mathrm{M} / 66$ & $S$ & $\mathrm{CC}$ & 6.6 & 1.4 & 2.3 & 1.4 & 1.0 & 2.2 & 1.7 \\
\hline 9 & $\mathrm{M} / 43$ & SR & $\mathrm{T}$ & 6.9 & 15.2 & 19.7 & 20.6 & 8.1 & 19.2 & 4.6 \\
\hline 10 & $\mathrm{M} / 74$ & $S$ & $\mathrm{~T}$ & 7.2 & 7.7 & 12.3 & 7.0 & 7.0 & 7.2 & 5.6 \\
\hline 11 & $M / 45$ & $S$ & TO & 7.9 & 8.2 & 15.1 & 9.9 & 4.7 & 12.5 & 3.8 \\
\hline
\end{tabular}

Preop therapy: $S$, steroids; $R$, radiation; $C$, chemotherapy.

Site: F, frontal; T, temporal; O, occipital; CC, corpus callosum.

FS, frozen section; PS, paraffin section.

${ }^{\star} 1$ st, first staining run with manual immunostaining; 2nd, second staining run with immunohistostainer. 
One result of this has been the development of Ki67 equivalent antibodies recognising the Ki67 antigen in microwave processed formalin fixed paraffin embedded sections. ${ }^{12-14}$ These preparations have several advantages over cryosections including better morphology, easier selection of representative areas, and the possibility for the examination of archival material. For these reasons, the immunohistochemical determination of proliferating activity should preferably be performed on paraffin sections.

The labelling indices obtained with the $\mathrm{Ki} 67$ equivalent antibodies were in accordance with other studies on glioblastoma tissues, both with regard to the prototypic Ki67 and MIB1. ${ }^{4-10}{ }^{17}$ The great spread of values reflects the pronounced heterogeneity of glioblastoma tissue. As the labelling indices overlap with those of low grade gliomas, immunohistochemical determination of proliferative activity in human gliomas must be assessed in combination with traditional histopathological findings. Only in some tumours did the antibodies reveal labelling indices within the same range, whereas in some cases a significant spread of values were found. There are no obvious reasons to explain these findings. In fact, this study was designed to be prospective in order to minimise potential sources of failure and to perform reliable comparisons of $\mathrm{Ki} 67 \mathrm{immu}-$ nostaining. The spread of labelling indices might be related to tumour heterogeneity, variable survival of the epitopes on the $\mathrm{Ki} 67$ antigen, and variable accessibility of the different epitopes after freezing, formalin fixation, paraffin embedding, and microwave oven heating; different degrees of antigen retrieval after microwave oven heating and conformational changes of the epitopes during the cell cycles are other possibilities. In general, little background staining was observed, but in a few cases the polyclonal antibodies displayed a weak non-specific staining that might have influenced the counting of weakly immunolabelled cells. In the duplicate stainings an immunohistostainer was used, representing a step towards a more automated and standardised immunohistochemistry. As the immunolabelling also varied in these experiments, this technique did not seem to have any influence upon Ki67 immunostaining. Differences in Ki67 immunostaining have been reported by others $^{15-17}$ and might be related to any of the factors mentioned above. Moreover, they might reflect the varying cut off values of the antibodies.

The variability of Ki67 immunostaining was suprising and may provoke some scepticism with regard to the immunohistochemical assessment of growth fractions in tumours using Ki67. Consequently, optimisation of the technique and large scale experiments could help define the clinical value of Ki67 immunostaining.
This study was supported by grants from the Cancer Fund at the University Hospital of Trondheim. The author thanks Borgny Ytterhus for excellent technical assistance.

1 Gerdes J, Schwab U, Lemke H, Stein H. Production of mouse monoclonal antibody reactive with a human nuclear antigen associated with cell proliferation. Int $\mathcal{f}$ Cancer 1983;31:13-20.

2 Gerdes J, Lemke H, Baisch $\mathrm{H}$, Wacker H-H, Schwab U, Stein $\mathrm{H}$. Cell cycle analysis of a cell proliferation-associated human nuclear antigen defined by the monoclonal antibody Ki67. $f$ Immunol 1984;133:1710-15.

3 Brown DC, Gatter KC. Monoclonal antibody Ki67; its use in histopathology. Histopathol 1990;17:489-503.

4 Morimura T, Kitz K, Stein H, Budka H. Determination of proliferation activities in human brain tumor specimens: a comparison of methods. $\mathcal{F}$ Neurooncol 1991;10:1-11.

5 Burger PC, Shibata T, Kleihues P. The use of the monoclonal antibody $\mathrm{Ki} 67$ in the identification of proliferating cells: application to surgical neuropathology. $A m \mathcal{F}$ Surg Pathol 1986;10:611-17.

6 Ostertag CB, Volk B, Shibata T, Burger P, Kleihues P. The monoclonal antibody $\mathrm{Ki} 67$ as a marker for proliferating cells in stereotactic biopsies of brain tumours. Acta Neuro chir (Wien) 1987;89:117-21.

7 Zuber P, Hamou M-F, de Tribolet N. Identification of proliferating cells in human gliomas using the monoclona Ki67. Neurosurgery 1988;22:364-8.

8 Raghavan R, Steart PV, Weller RO. Cell proliferation patterns in the diagnosis of astrocytomas, anaplastic astrocytomas and glioblastoma multiforme: a Ki67 study. Neuropath Appl Neurobiol 1990;16:123-33.

9 Montine TJ, Vandersteenhoven J, Aguzzi A, Boyko OB, Dodge RK, Kerns, et al. Prognostic significance of Ki67 proliferation index in supratentorial fibrillary astrocytic neoplasms. Neurosurgery 1994;34:674-9.

10 Jaros E, Perry RH, Adam L, Kelly PJ, Crawford PJ, Kalbag $\mathrm{RM}$, et al. Prognostic implications of p53 protein epidermal growth factor receptor, and $\mathrm{Ki} 67$ labelling in brain tumours. Br $\mathcal{F}$ Cancer 1992;66:373-85

11 Torp SH, Helseth E, Dalen A, Unsgaard G. Relationships between Ki67 labelling index, amplification of the epidermal growth factor receptor gene, and prognosis in human glioblastomas. Acta Neurochir (Wien) 1992;117:182-6.

12 Cattoretti G, Becker MHG, Key G, Duckrow M, Schlüter C, Galle J, et al. Monoclonal antibodies against recombinant parts of the Ki67 antigen (MIB 1 and MIB 3) detect proliferating cells in microwave-processed formalin-fixed paraffin sections. $\mathcal{F}$ Pathol 1992;168:357-63.

13 Key G, Becker MHG, Baron B, Duchrow M, Schlüter C Flad H-D, et al. New Ki67-equivalent murine monoclonal antibodies (MIB 1-3) generated against bacterially expressed parts of the Ki67 cDNA containing three 62 base pair repetitive elements encoding for the Ki67 epitope. $L a b$ Invest 1993;68:629-36.

14 Key G, Petersen JL, Becker MHG, Duckrow M, Schlüter C, Askaa J, et al. New antiserum against Ki67 antigen suitable for double immunostaining of paraffin wax sections. 7 Clin Pathol 1993;46:1080-4.

15 Barbareschi M, Girlando S, Mauri FM, Forti S, Eccher C. Mauri FA, et al. Quantitative growth fraction evaluation with MIB1 and Ki67 antibodies in breast carcinomas. $\mathrm{Am}$ 7 Clin Pathol 1994;102:171-5.

16 Mazerolles C, Rishmann P, Chopin D, Popov Z, Malavud B, Selves J, et al. Usefulness of MIB1 monoclonal antibody in assessing the proliferative index in human bladder carcinoma: comparison with $\mathrm{Ki} 67$ antibodies. Histopathology 1994;25:563-8.

17 Onda K, Davis RL, Shibuya M, Wilson CB, Hoshino T. Correlation between the bromodeoxyuridine labeling index and the MIB-1 and Ki67 proliferating cell indices in cerebral gliomas. Cancer 1994;74:1921-6.

18 Torp SH, Johannesen E, Lindboe CF. Comparison of different Ki67 antibodies in human glioblastomas. $\mathcal{F}$ Clin Pathol: Mol Pathol 1995;48:M191-3.

19 World Health Organisation. Histological typing of tumours of the central nervous system. In: International histological classification of tumours. 2nd edn. Berlin: Springer-Verlag, 1993:1-30.

20 Cuevas E, Jones DB, Wright DH. Immunohistochemical detection of tumor growth fraction (Ki67 antigen) in formalin-fixed and routinely processed tissues. $\mathcal{F}$ Pathol 1993;169:477-8.

21 Rose DSC, Maddox PH, Brown DC. Which proliferation markers for routine immunohistology? A comparison of five antibodies. $f$ Clin Pathol 1994;47:1010-14. 